\title{
Greve dos caminhoneiros e concentração de poluentes na Baixada Fluminense, Rio de Janeiro, Brasil
}

O principal objetivo desse trabalho foi avaliar as concentrações de poluentes em duas estações de monitoramento contínuo de poluentes localizadas na Baixada Fluminense, estado do Rio de Janeiro, Brasil, durante o período de greve dos caminhoneiros, entre os dias 21 e 30 de maio de 2018. As duas estações - Jardim Primavera e Jardim Guandu - podem ser consideradas rotas de entrada/saída do município do Rio de Janeiro. Foram analisadas as concentrações dos seguintes poluentes: dióxido de enxofre, monóxido de carbono, ozônio, material particulado (PM10) e dióxido de nitrogênio. Os dados abrangeram o período de 7 de maio a 13 de junho de 2018, sendo divididos em dois diferentes grupos: período de greve e período fora da greve. Uma das ferramentas utilizadas para análise foi o diagrama de caixa, apresentando, para o período analisado, a concentração diária de cada poluente e seu respectivo comportamento. Para comparar o comportamento dos poluentes durante a greve dos caminhoneiros e suas proximidades, efetuou-se um teste de homogeneidade entre os dois grupos, sendo aplicado o teste de variâncias iguais. Para as situações que indicaram a hipótese de não homogeneidade entre os dois grupos foi acrescentado o teste $t$ student, visando avaliar se havia diferença significativa entre as médias dos diferentes períodos. Comparando-se o período de greve e o período não greve, o dióxido de enxofre foi o único poluente que não apresentou diferença de comportamento em ambas as estações. O monóxido de carbono apresentou diminuição de concentração média nas duas estações durante o período da greve, o que pode ser resultado do efeito da paralisação dos veículos automotores nesse período. O dióxido de nitrogênio também apresentou menor concentração durante o período de greve em ambas as estações, tendo o ozônio apresentado comportamento inverso, efeito da relação entre os Compostos Orgânicos Voláteis e os Óxidos de Nitrogênio. O material particulado apresentou redução das concentrações em Jardim Primavera durante a greve, mas com elevação em Jardim Guandu no mesmo período. Hipótese para essa elevação seria o uso das vias próximas a Jardim Guandu como alternativa de rota de fuga dos caminhoneiros. Acredita-se que o presente trabalho possa contribuir para a identificação dos impactos, em termos de poluição atmosférica, causados pela opção preferencial dada aos caminhões para o transporte das cargas no Brasil.

Palavras-chave: Óleo diesel; Poluição atmosférica; Transporte de cargas; Greve dos caminhoneiros; Estações de Monitoramento.

\section{Truckers' strike and pollutant concentration in the Baixada Fluminense, Rio de Janeiro, Brazil} \begin{abstract}
The main objective of this work was to evaluate the concentrations of pollutants in two monitoring stations for pollutants located in Baixada Fluminense, Rio de Janeiro state, Brazil, during the truck drivers' strike period, between May 21 and 30, 2018. The two stations - Jardim Primavera and Jardim Guandu - can be considered entry/exit routes in the city of Rio de Janeiro. The
concentrations of the following pollutants were analysed: sulfur dioxide, carbon monoxide, ozone, particulate matter (PM10) and nitrogen dioxide. The data covered the period from May 7 to June 13,2018 , and were divided into two different groups: strike period and period outside it. One of the tools used for analysis was the box diagram, presenting the daily concentration of each pollutant and its respective behavior. In order to compare the behavior of the pollutants during the strike of truck drivers and their proximity, a homogeneity test between the two groups was carried out, being applied the test of equal variances. For situations that indicated the hypothesis of non homogeneity between the two groups, the $t$ student test was added, in order to evaluate if there was significant difference between the means of the different periods. Comparing the strike period and the no strike period, sulphur dioxide was the only pollutan that did not show difference in behavior in both stations. Carbon monoxide showed a decrease of average concentration in both stations during the strike period, which can be a result of the effect of the motor vehicles paralysis in that period. Nitrogen dioxide also showed lower concentration during the strike period in both stations. Ozone had inverse behavior, which was effect the relation effect of there with elevation in Jardim Guandu during the same period. Hypothesis for this elevation would be the use of the roads close to Jardim Guandu as an alternative escape route for truck drivers. It is believed that the present work can contribute to the identification of the impacts, in terms of atmospheric pollution, caused by the preferential option given to trucks for the transportation of cargo in Brazil.
\end{abstract}

Keywords: Diesel oil; Air pollution; Cargo transportation; Truckers strike; Monitoring Stations.

Topic: Sustentabilidade nos Transportes

Reviewed anonymously in the process of blind peer.
Received: 02/02/2021

Approved: 27/02/2021
Maxime Charles-Pierre (id

Universidade Veiga de Almeida, Brasil http://lattes.cnpq.br/7045279336950644

http://orcid.org/0000-0002-4552-6220

maximecp@yahoo.fr

Cleyton Martins da Silva (D)

Universidade Veiga de Almeida, Brasil

http://lattes.cnpq.br/2637457192603373

http://orcid.org/0000-0002-5216-4977

cleyton.silva@uva.br

Wagner de Souza Pereira

Universidade Veiga de Almeida, Brasil

http://lattes.cnpq.br/4831334377580644

pereiraws@gmail.com

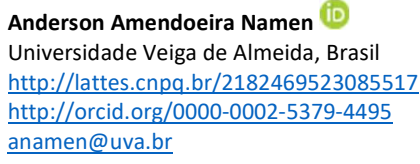

Anderson Amendoeira Namen (iD)

Universidade Veiga de Almeida, Brasil

http://lattes.cnpq.br/2182469523085517

http://orcid.org/0000-0002-5379-4495

anamen@uva.br

Referencing this:

CHARLES-PIERRE, M.; SILVA, C. M.; PEREIRA, W. S.; NAMEN, A. A. Greve dos caminhoneiros e concentração de poluentes na Baixada Fluminense, Rio de Janeiro, Brasil. Revista Ibero Americana de Ciências Ambientais, v.12, n.2, p.394-409, 2021. DOI: http://doi.org/10.6008/CBPC2179-6858.2021.002.0034 


\section{INTRODUÇÃO}

Com o crescimento do desenvolvimento industrial, a poluição ambiental tornou-se algo evidente, causando danos severos à saúde das populações (KARIMI et al., 2020). Ao lado da amplificação das atividades industriais, ocorreu o crescente trânsito de veículos, resultando em um maior comprometimento da qualidade do ar, problema também influenciado por fatores climáticos, que podem dificultar a dispersão dos poluentes (PIRES, 2005). Estudos experimentais e epidemiológicos confirmam a associação entre a poluição do ar e os níveis de mortalidade devido a problemas cardiopulmonares e respiratórios, assim como um aumento nas internações hospitalares causadas pelas doenças respiratórias e cardiovasculares (MANNUCCI et al., 2015, COHEN et al., 2017).

A emissão de poluentes atmosféricos oriunda de atividades antrópicas se dá tanto por fontes fixas quanto por fontes móveis. As fontes fixas se referem às atividades da indústria de transformação, mineração e produção de energia em uma área determinada. As fontes móveis, foco da presente pesquisa, consistem nos meios de transporte aéreo, marítimo e terrestre que utilizam motores a combustão (CASTRO et al., 2013).

Segundo Lima (2018), o Brasil possui cerca de 2 milhões de caminhoneiros, sendo que $61 \%$ do transporte de cargas no Brasil é feito pelas rodovias, número muito superior a países como Austrália (53\%), China (50\%), Canadá (43\%), Estados Unidos (32\%) e Rússia (8\%). Salienta-se que o transporte rodoviário é um modal caro e energeticamente ineficiente, uma vez que o consumo de combustível para transportar uma tonelada de carga por mil quilômetros fazendo uso de caminhões é 2,7 vezes superior ao consumo dos trens e 3,8 vezes maior do que o consumo de navios (REZENDE, 2017).

Conforme discussão de Watanabe et al. (2018) a greve dos caminhoneiros, ocorrida entre os dias 21 e 30 de maio de 2018, explicitou o esgotamento do modelo dependente das rodovias e combustíveis fósseis e seu impacto na segurança logística do país. Segundo a agência de notícias BBC-Brasil (2018), foram duas motivações que levaram os caminhoneiros à greve: a elevação do preço do litro do diesel e a demanda pela fixação de uma tabela mínima para os valores do frete. Os caminhões ocuparam as rodovias desde os primeiros dias do movimento e provocaram um bloqueio parcial das principais vias de acesso. Após alguns dias os postos de combustíveis, supermercados, escolas e hospitais passaram a sentir o efeito da paralisação por falta de abastecimento dos caminhões, inclusive com consequências para os ônibus, também movidos por óleo diesel. No dia 29 de maio, $90 \%$ dos postos de combustíveis ficaram sem os seus produtos para venda ao consumidor (BBC-BRASIL, 2018).

O referido evento se apresentou como uma ocasião única para avaliar, a partir de dados coletados em estações que monitoram a qualidade do ar, até que ponto a opção preferencial dada aos caminhões para o transporte das cargas, e posteriormente, a diminuição de ônibus, veículos leves e motocicletas, pode impactar o meio ambiente. Trata-se de uma ocasião única pelo fato de que nunca houve uma paralização de tal magnitude, caracterizando-se com relevância para o debate público e científico. Nesse sentido, esse trabalho objetiva avaliar, em duas estações de monitoramento da qualidade do ar localizadas na baixada fluminense do estado do Rio de Janeiro, as concentrações dos seguintes poluentes: dióxido de enxofre $\left(\mathrm{SO}_{2}\right)$, 
monóxido de carbono $(\mathrm{CO})$, ozônio $\left(\mathrm{O}_{3}\right)$, material particulado $\left(\mathrm{PM}_{10}\right)$ e dióxido de nitrogênio $\left(\mathrm{NO}_{2}\right)$.

\section{MATERIAIS E MÉTODOS}

\section{Área de estudo}

As duas estações de monitoramento contínuo de poluentes escolhidas são automáticas e coletam dados sobre as concentrações dos poluentes $\mathrm{SO}_{2}, \mathrm{CO}, \mathrm{O}_{3}, \mathrm{PM}_{10}$ e $\mathrm{NO}_{2}$ a cada intervalo de uma hora. As estações, denominadas Jardim Primavera e Jardim Guandu, estão situadas, respectivamente, nos municípios de Duque de Caxias e Nova Iguaçu, localizados na baixada fluminense, na região metropolitana, e fronteiriços ao município do Rio de Janeiro (Figura 1a). Essas estações foram escolhidas por se localizarem em rotas estratégicas de entrada/saída da cidade do Rio de Janeiro. A estação Jardim Primavera localiza-se perto de rodovias que fazem ligação com as regiões norte, nordeste e centro-oeste; e Jardim Guandu com a região sul. As duas estações estão distantes entre si por uma extensão de 63,5km. A estação Jardim Primavera, ao lado direito da figura, encontra-se muito próxima à baía de Guanabara; ao seu lado, a $5 \mathrm{~km}$ no sentido sul marcada em laranja (Figura 1b), encontra-se a refinaria Duque de Caxias (REDUC), que constitui uma fonte fixa importante de emissões atmosféricas (INEA, 2015). O Instituto Estadual do Ambiente (INEA) disponibiliza em seu site um link para acesso aos dados, que são coletados diretamente das estações de monitoramento, validados pela sua equipe técnica e, após validação, disponibilizados para acesso público.

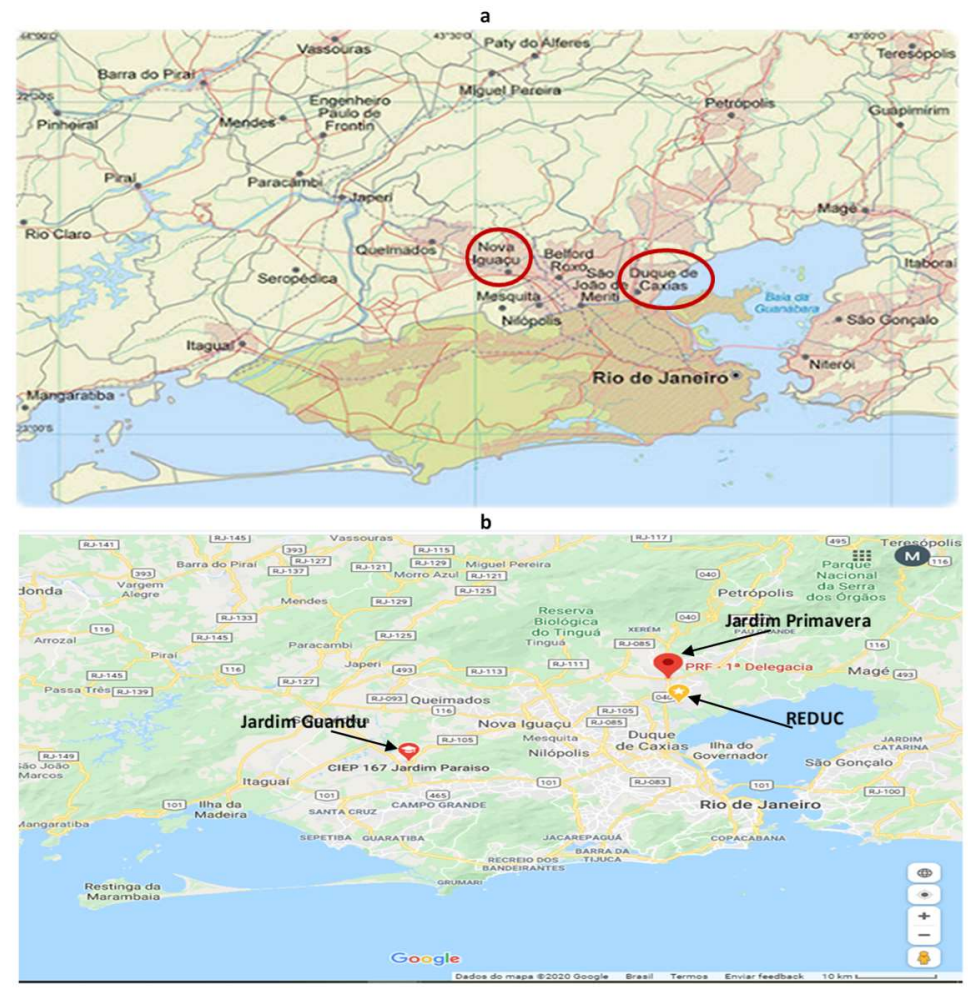

Figura 1: Localização das estações Jardim Primavera e Jardim Guandu.

(a) Mapa do município do Rio de Janeiro e proximidades, com indicação dos municípios de Nova Iguaçu e Duque de Caxias. (b) Localização das estações e da REDUC. Fonte: Google Maps.

\section{Período escolhido e coleta de dados}

Como a greve dos caminhoneiros ocorreu entre os dias 21 e 30 de maio de 2018, foram considerados, 
além do período de greve, 14 dias anteriores e posteriores a esse período para efeito de comparação com o período de greve, resultando em um período compreendido entre 07 de maio e 13 de junho de 2018. Esses 28 dias, para fins de análise, foram então divididos em dois diferentes grupos: período de greve e período fora da greve. Houve coleta de um total de 912 registros de dados, correspondentes a 24 horas multiplicadas por 38 dias de monitoramento. Para o tratamento estatístico dos dados obtidos, utilizou-se o software MINITAB como ferramenta de apoio (MINITAB, 2017).

\section{Análise diária das concentrações de poluentes}

Uma das abordagens utilizadas para análise dos dados foi o diagrama de caixa (boxplot), apresentando, para o período de 7 de maio a 13 de junho de 2018, as concentrações diárias de cada poluente e o seu respectivo comportamento. Segundo Dawson (2011), esse diagrama consiste em uma caixa que se estende do primeiro quartil $\left(Q_{1}\right)$ ao terceiro quartil $\left(Q_{3}\right)$. Dentro da caixa se encontra uma marca na mediana; além disso, hastes se estendem do primeiro quartil ao limite inferior e do terceiro quartil ao limite superior. Os limites são calculados a partir das seguintes equações:

Limite inferior: $\max \left\{\min \left(\right.\right.$ dados); $\left.Q_{1}-1,5\left(Q_{3}-Q_{1}\right)\right\}$

Limite superior: $\min \left\{\max (\right.$ dados $\left.) ; Q_{3}+1,5\left(Q_{3}-Q_{1}\right)\right\}$

Pontos fora destes limites são considerados valores discrepantes (outliers) e são denotados no diagrama por asterisco, entretanto, por se tratar de um monitoramento ambiental, não podem ser desconsiderados, visto que os dados ambientais são comumente considerados como não-paramétricos. Em relação às hastes mencionadas, hastes curtas podem indicar uma distribuição uniforme com pontos de cortes acentuados.

O diagrama de caixa é usado com o objetivo de permitir a visualização de alguns conceitos como a simetria, a dispersão ou a centralidade da distribuição dos valores associados a uma variabilidade (TUKEY, 1977; CHAMBERS, 1983). Nesta ordem de ideia, o diagrama permite comparar as variáveis em relação a escalas similares e comparar os valores das observações de grupos de indivíduos sobre uma mesma variabilidade. Nesse sentido, a apresentação do boxplot para o período de 7 de maio a 13 de junho de 2018 visou auxiliar na compreensão da repartição das observações de cada um dos poluentes em cada um dos dias analisados.

$\mathrm{Na}$ apresentação dos diagramas de caixa, foram observados os padrões de qualidade do ar para os diferentes poluentes estabelecidos pela resolução 491/2018 do Conselho Nacional do Meio Ambiente CONAMA (CONAMA, 2018). Essa resolução adotou os seguintes padrões: padrões de qualidade do ar intermediários - PI (níveis 1 a 3), que são padrões estabelecidos como valores temporários a serem cumpridos em etapas; padrão de qualidade do ar final - PF, baseado em parâmetros definidos pela Organização Mundial da Saúde (OMS) em 2005. Para os casos em que as concentrações de poluentes ultrapassaram qualquer dos padrões definidos na resolução (Tabela 1), essa indicação foi destacada no diagrama apresentado. 
Tabela 1: Padrões nacionais da qualidade do ar.

\begin{tabular}{|c|c|c|c|c|c|c|}
\hline Poluente Atmosférico & Período de Referência & $\begin{array}{l}\text { PI-1 } \\
\mu \mathrm{g} / \mathrm{m}^{3}\end{array}$ & $\begin{array}{l}\text { PI-2 } \\
\mu \mathrm{g} / \mathrm{m}^{3}\end{array}$ & $\begin{array}{l}\text { PI-3 } \\
\mu \mathrm{g} / \mathrm{m}^{3}\end{array}$ & $\begin{array}{l}\text { PF } \\
\mu \mathrm{g} / \mathrm{m}^{3}\end{array}$ & $\mathrm{ppm}$ \\
\hline \multirow[t]{2}{*}{ Material Particulado - $\mathrm{PM}_{10}$} & 24 horas & 120 & 100 & 75 & 50 & - \\
\hline & Anual $^{1}$ & 40 & 35 & 30 & 20 & - \\
\hline \multirow[t]{2}{*}{ Dióxido de Enxofre - $\mathrm{SO}_{2}$} & 24 horas & 125 & 50 & 30 & 20 & - \\
\hline & Anual ${ }^{1}$ & 40 & 30 & 20 & - & - \\
\hline \multirow[t]{2}{*}{ Dióxido de Nitrogênio - $\mathrm{NO}_{2}$} & 1 hora $^{2}$ & 260 & 240 & 220 & 200 & - \\
\hline & Anual $^{1}$ & 60 & 50 & 45 & 40 & - \\
\hline Ozônio - $\mathrm{O}_{3}$ & 8 horas $^{3}$ & 140 & 130 & 120 & 100 & - \\
\hline Monóxido de Carbono - $\mathrm{CO}^{4}$ & 8 horas $^{3}$ & - & - & - & - & 9 \\
\hline \multicolumn{7}{|l|}{1 - média aritmética anual } \\
\hline \multicolumn{7}{|c|}{2 - média horária } \\
\hline \multicolumn{7}{|c|}{3 - máxima média móvel obtida no dia } \\
\hline \multicolumn{7}{|c|}{4 - para o monóxido de carbono foi adotado unicamente o padrão de qualidade de ar final } \\
\hline
\end{tabular}

Fonte: Adaptado de CONAMA (2018).

\section{Comparação entre os períodos - greve versus próximo à greve}

Para comparar o comportamento dos poluentes durante a greve dos caminhoneiros e suas proximidades, efetuou-se um teste de homogeneidade entre dois grupos. De um lado, o grupo com os dados das concentrações de poluentes nos períodos exteriores à greve (antes e depois da mesma), e do outro, o grupo com os dados referentes ao período de greve. Para isso foi aplicado o teste de variâncias iguais. Conforme Jayalath et al. (2017), o teste de variâncias iguais pode ser aplicado em muitas áreas de pesquisa, incluindo controle de qualidade, processos de manufatura e na ecologia, entre outras. Dentro do software MINITAB, utilizado na presente pesquisa, esse teste exibe resultados para o método de múltiplas comparações e para o método de Levene. Para distribuições mais contínuas, os dois métodos fornecem uma taxa de erro tipo I próxima do nível de significância especificado (conhecido como alfa). O método de múltiplas comparações é geralmente mais robusto. O valor $p$ obtido, com auxílio do software, para o método de múltiplas comparações é considerado não significante se for igual ou maior que 0,05 . Nesse caso, não se rejeita a hipótese de homogeneidade das variâncias. Em situação distinta $(p<0,05)$, rejeita-se a hipótese de homogeneidade, podendo-se então considerar que há diferenças entre os grupos analisados.

O método de múltiplas comparações é suficiente para a obtenção de conclusões em relação à homogeneidade ou não dos grupos, exceto se as seguintes condições forem verdadeiras: 1) As amostras possuírem menos de 20 observações cada; 2) A distribuição para uma ou mais das populações for extremamente assimétrica ou tiver caudas pesadas. Em comparação com a distribuição normal, uma distribuição com caudas pesadas tem mais dados nas suas extremidades inferiores e superiores.

Quando existem pequenas amostras de distribuições muito assimétricas ou com caudas pesadas, se o método de Levene proporcionar um valor de $\mathrm{p}$ menor do que o método de múltiplas comparações, é possível usar como base os resultados obtidos pelo método de Levene, considerando mais uma vez o limiar de 0,05 como indicador quanto à homogeneidade $(p \geq 0,05)$ ou não $(p<0,05)$ dos grupos analisados (MINITAB, 2017).

Em suma, usou-se a abordagem de aplicar o teste de variâncias iguais para identificar se houve ou não homogeneidade nos comportamentos das concentrações de poluentes, comparando-se o período de greve com o período externo a ela. Ressalta-se que a ferramenta utilizada disponibiliza um gráfico que ilustra 
o teste de homogeneidade. Nesse gráfico, cada período amostral é calculado aplicando-se o intervalo de confiança de 95\% de Bonferroni (MINITAB, 2017). A referência utilizada é o valor da concentração média do poluente para cada período; o intervalo de confiança citado define, nesse sentido, uma faixa de valores, com a garantia de não se ultrapassar um limite mínimo e um limite máximo, sendo esse intervalo apresentado no gráfico. Mais detalhes sobre o método de Bonferroni podem ser encontrados em Rumsey (2018).

Para as situações em que os valores de $p$ indicaram a hipótese de não homogeneidade entre os dois grupos $(p<0,05)$, foi acrescentado, em um segundo momento, o teste $t$ student, visando avaliar se havia diferença significativa entre as médias dos diferentes grupos analisados. Nessa segunda etapa, avaliou-se o valor $\mathrm{p}$ obtido no teste $t$ student, sendo que resultados inferiores a 0,05 indicariam diferenças significativas nas médias dos grupos amostrais (MINITAB, 2017).

\section{RESULTADOS E DISCUSSÃO}

\section{Concentrações de $\mathrm{SO}_{2}$}

Na Figura 2 são apresentados os diagramas de caixa referentes às concentrações de dióxido de enxofre nas estações Jardim Primavera e Jardim Guandu no período de 7 de maio a 13 de junho de 2018. As caixas referentes aos dias próximos à greve são apresentadas em cor azul; as que se referem ao período de greve, em cor verde. Essa diferenciação de cores será mantida na apresentação de todos os diagramas de caixa listados posteriormente nesse trabalho. Registros de outliers são apresentados em asterisco. Visando facilitar as análises, é possível visualizar nos gráficos os valores limitantes de padrão final de qualidade do ar (PF) definido pela OMS e do padrão intermediário de nível 1 (PI-1), atualmente em vigor de acordo com a resolução 491 de 2018 do CONAMA (CONAMA, 2018).

a

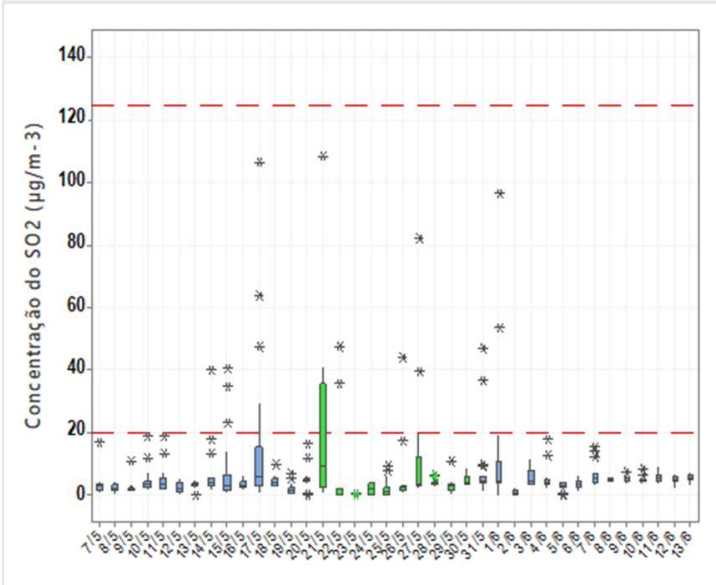

b

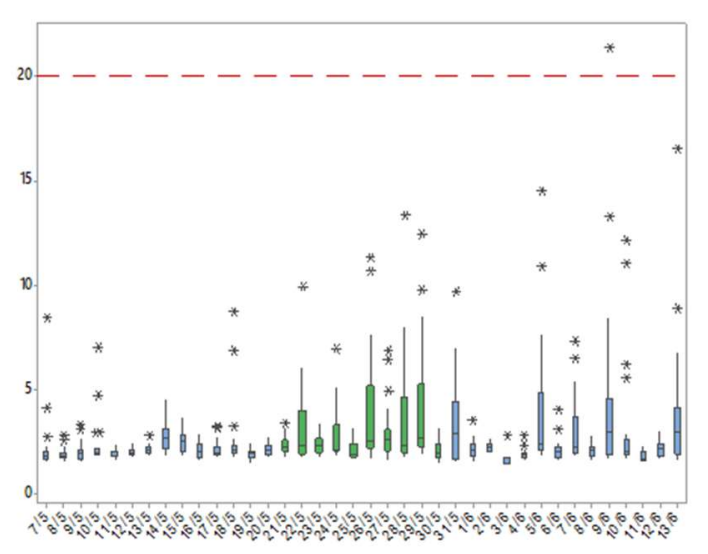

Figura 2: Variação das concentrações de $\mathrm{SO}_{2}$ - (a) Jardim Primavera, (b) Jardim Guandu.

Observa-se que Jardim Guandu apresenta concentrações bem menores, considerando todo o período analisado, em comparação com as concentrações apresentadas na estação Jardim Primavera. Esta última apresenta concentrações que superam o padrão estabelecido pela OMS e alguns outliers com valores de concentração altos, próximos ao padrão intermediário de nível I estabelecido pelo CONAMA, mas sem ultrapassá-los. 
Aplicou-se então o teste de variâncias iguais para identificar se houve ou não homogeneidade nos comportamentos das concentrações de poluentes, comparando-se os dois grupos de dados: período de greve e período fora da greve (Figura 3 ).

a

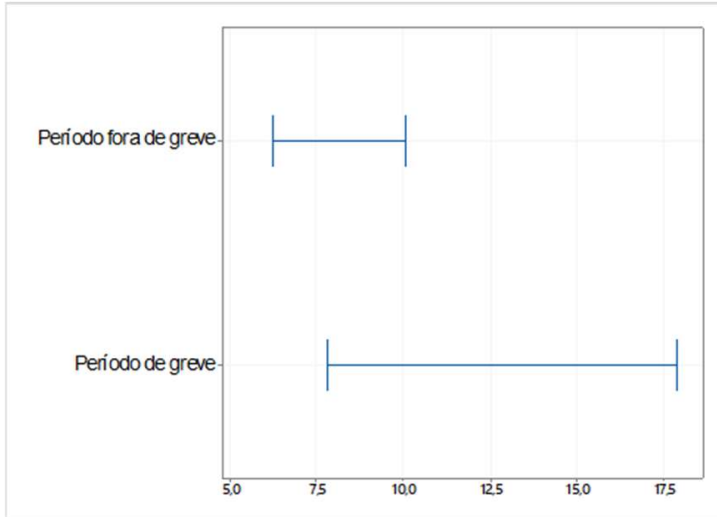

b

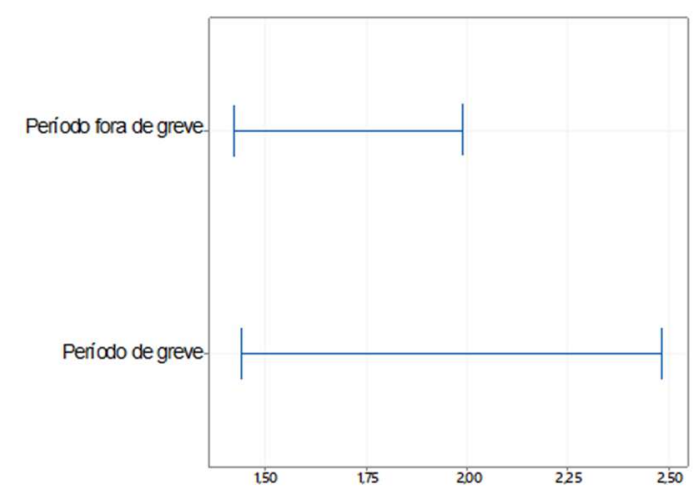

Figura 3: Teste de variâncias iguais - Concentrações de $\mathrm{SO}_{2}$. (a) Jardim Primavera, (b) Jardim Guandu.

Os gráficos (Figura 3) indicam, tanto para Jardim Primavera quanto Jardim Guandu, que não se pode rejeitar a hipótese de homogeneidade entre os 2 grupos analisados, uma vez que os valores de p para o teste de comparações múltiplas ( $p$-Valor, apresentado na extremidade superior direita dos gráficos) não foram significativos $(p>0,05)$. Como as amostras possuíam mais de 20 registros e não se caracterizavam como assimétricas, a análise do valor de $p$ para o teste de Levene ( $p$-Valor, também localizado na extremidade superior direita da imagem) se tornou desnecessária. Observa-se nos gráficos que os valores do intervalo fora greve se sobrepõem aos valores do período de greve, confirmando certo grau de homogeneidade entre os dois períodos. Em suma, pode-se constatar que as duas estações não apresentaram diferença de comportamento nos dois períodos amostrais (durante e fora da greve). Uma possível explicação para esses resultados seria a tendência de redução nas concentrações de enxofre nos combustíveis no Brasil. As normas relacionadas ao teor de enxofre passaram a exigir, a partir de 2014, uma redução para no máximo 50 ppm do poluente; para o diesel, a partir de 2013 os teores passaram a ser limitados a 500 ppm em cidades do interior e a 10 ppm nas metrópoles (MELLO et al., 2018). Nesse sentido, os efeitos do volume de tráfego de veículos passaram a ser menos evidentes, fato comprovado pelos resultados aqui apresentados.

\section{Concentrações de CO}

É notório observar as baixas concentrações do monóxido de carbono nas 2 estações no período analisado (Figura 4). Uma provável explicação seriam as medidas adotadas pelo estado de Rio de janeiro, a partir do decreto 22.599/96, contendo exigências mais rígidas relacionadas à vistoria anual do Departamento de Trânsito de Rio de Janeiro (DETRAN-RJ), a fim de controlar as emissões de poluentes produzidos pelos veículos (RIO DE JANEIRO, 1996). Na estação Jardim Primavera observa-se que depois do dia 25 de maio, os boxplots ilustraram menores concentrações de monóxido de carbono até o penúltimo dia da greve (Figura 4a). Ressalta-se que, a partir dessa data, começou a haver escassez de gasolina e diesel nos postos de combustíveis para o abastecimento dos veículos leves e pesados (BBC-BRASIL, 2018). 
Salienta-se que entre os dias 5 e 13 de junho a estação Jardim Guandu não coletou os dados dos poluentes. Assim, o diagrama de caixa (Figura 4b) não se estendeu até dia 13 de junho. Nessa estação podese observar que as concentrações medianas nos cinco primeiros dias da greve foram maiores em comparação com os cinco últimos dias. Assim como na avaliação realizada na estação Jardim Primavera, isto poderia ser explicado pelo fato de que no início da greve ainda havia tráfego de veículos leves, o que foi reduzido nos últimos dias devido à carência de combustível nos postos (BBC-BRASIL, 2018).

a

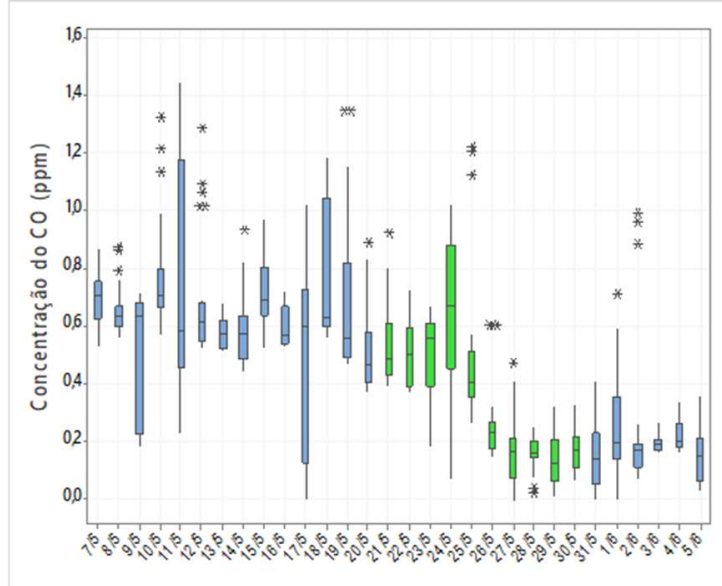

b

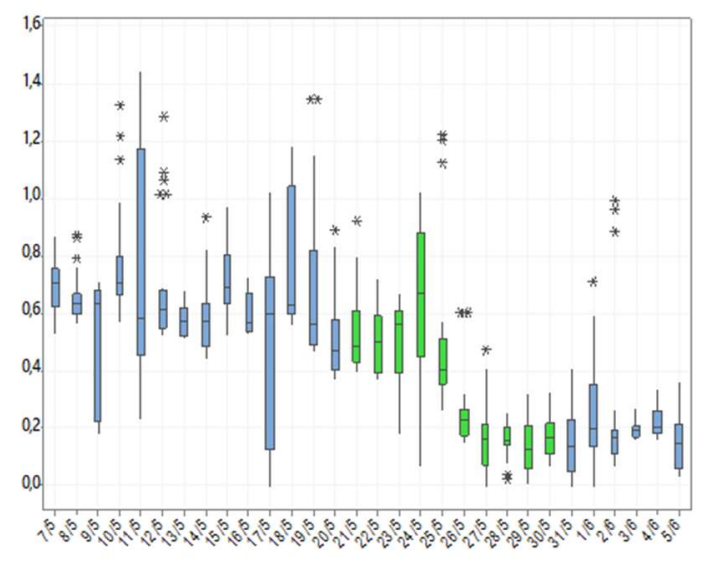

Figura 4: Variação das concentrações de CO - (a) Jardim Primavera, (b) Jardim Guandu.

Ao analisar o comportamento do poluente nos dois períodos (dentro e fora da greve), observa-se que para a estação Jardim Primavera os valores de p, tanto para o teste de comparações múltiplas $(0,017)$ quanto para o teste de Levene $(0,006)$, possuem real significância, podendo ser rejeitada a hipótese de homogeneidade das variâncias (Figura 5a). Em Jardim Guandu, o valor de p obtido para o método de comparações múltiplas foi de 0,004, muito inferior a 0,05, podendo-se também afirmar que houve diferença estatística significativa entre os dois períodos (Figura 5b). A não homogeneidade fica clara a partir dos intervalos dos 2 grupos (período dentro e fora da greve) apresentados em ambos os gráficos, que não se sobrepuseram.

Uma vez constatada a não homogeneidade, foi feito um teste $t$ student, visando avaliar se havia diferença significativa entre as médias dos diferentes grupos. O valor de p obtido para esse teste para ambas as estações foi igual a 0 , confirmando a hipótese de real diferença entre os dois períodos. Em Jardim Primavera, para o período de greve, a concentração média obtida no teste $t$ student foi de $0,45 \mathrm{ppm}$, sendo de 0,64ppm para os períodos externos à greve. Já para Jardim Guandu, a concentração média durante o período da greve foi de 0,33ppm, sendo de 0,52ppm nos períodos próximos a ela. Assim, pode-se concluir que o monóxido de carbono teve uma concentração menor durante o período da greve nas duas estações (30\% em Jardim Primavera e 37\% em Jardim Guandu) em comparação com os períodos próximos à mesma. 


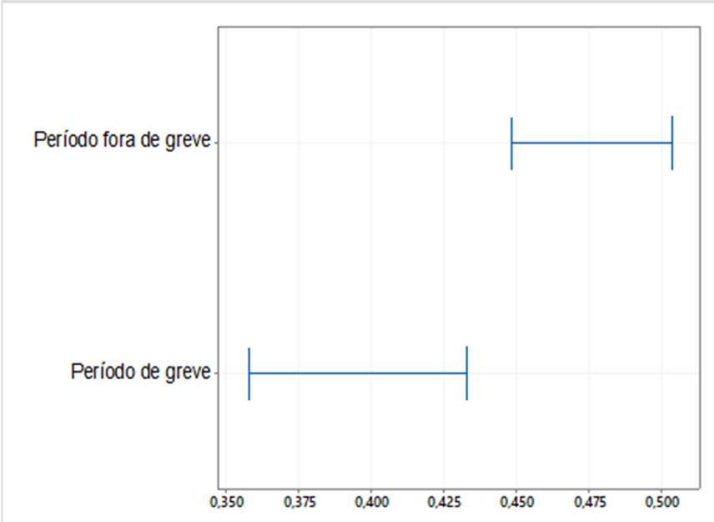

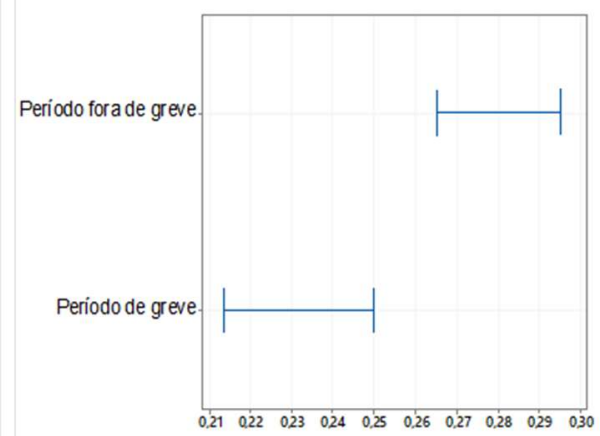

Figura 5: Teste de variâncias iguais - Concentrações de CO. (a) Jardim Primavera, (b) Jardim Guandu.

\section{Concentrações de $\mathrm{NO}_{2}$}

Uma vez que o padrão de qualidade de ar final estabelecido pela OMS para uma média horaria é de $200 \mu \mathrm{g} \mathrm{m}^{-3}$ (CONAMA, 2018), observa-se que os níveis de concentrações do poluente na estação Jardim Primavera, por todo o período, se encontravam em faixas totalmente satisfatórias (Figura 6a). Pode-se notar também que a partir do quarto dia de greve e até o seu término, as concentrações do dióxido de nitrogênio apresentaram variações dentro de faixas de valores inferiores, quando comparadas com os outros dias. 0 dia 31 de maio, data que coincide com o início das elevações nas concentrações, expressa a retomada das atividades, com os reabastecimentos dos postos de combustível (BBC-BRASIL, 2018).

Para a estação Jardim Guandu constata-se que as concentrações do poluente (Figura 6 b) foram bem mais elevadas do que as obtidas na estação Jardim Primavera; apesar disso, essas ainda se encontram dentro dos padrões estabelecidos pelo CONAMA. Nota-se, de uma maneira geral, que as faixas de variações (e das medianas) das concentrações do $\mathrm{NO}_{2}$ durante a greve apresentam valores inferiores em relação aos períodos anterior e posterior a mesma.

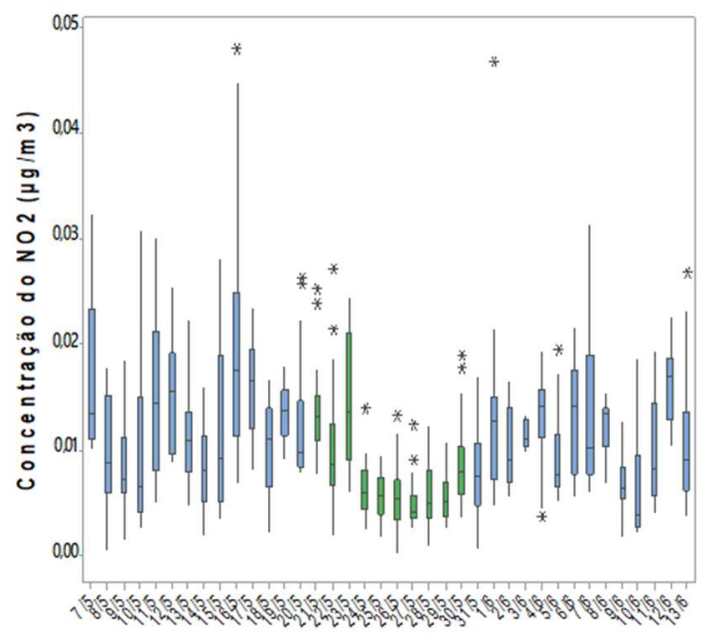

b

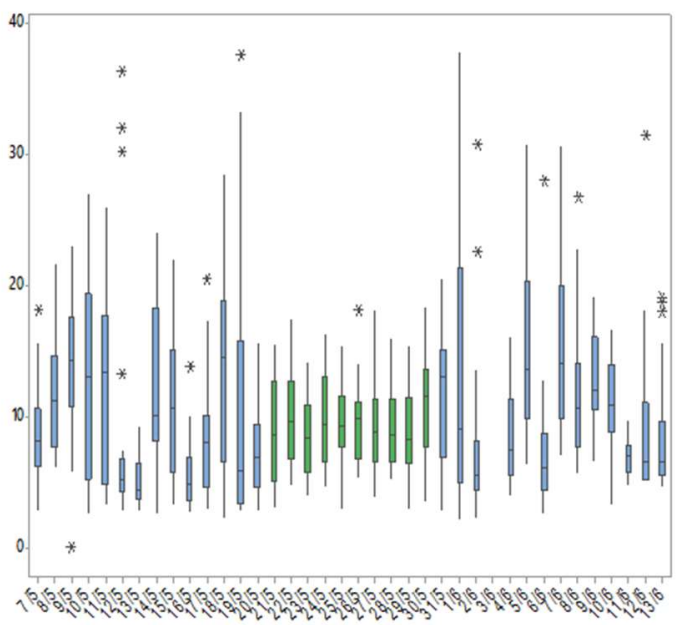

Figura 6: Variação das concentrações de $\mathrm{NO}_{2}$ - (a) Jardim Primavera, (b) Jardim Guandu.

Considerando o valor de $p$ para o método de comparações múltiplas (Jardim Primavera $-p=0,009$; Jardim Guandu $-p=0$ ), a hipótese de homogeneidade foi rejeitada para ambas as estações (Figura 7). 


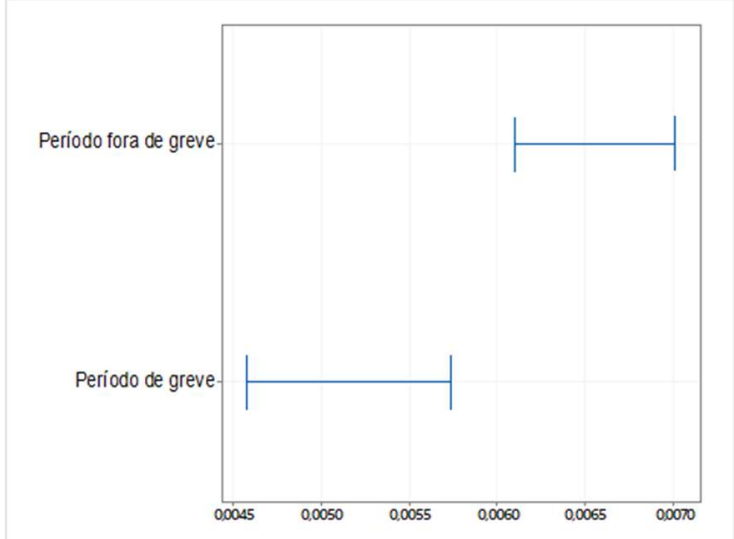

b

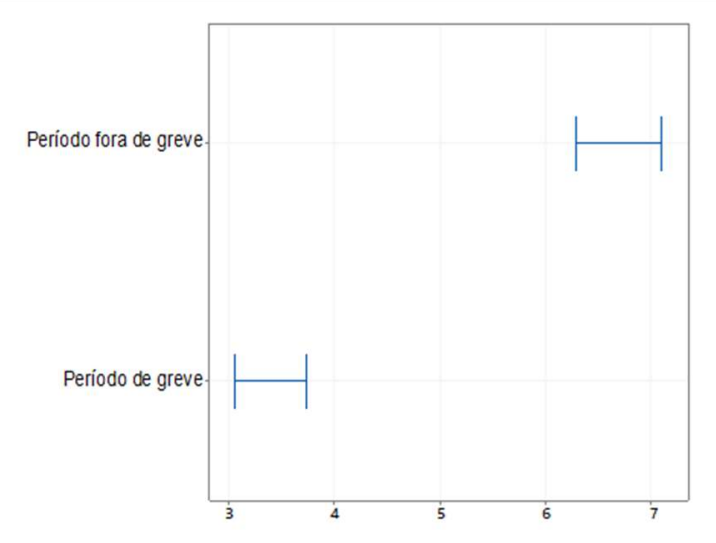

Figura 7: Teste de variâncias iguais - Concentrações de NO2. (a) Jardim Primavera, (b) Jardim Guandu.

O teste $t$ student, (Jardim Primavera $-p=0$; Jardim Guandu $-p=0,001$ ) comprovou as diferenças de comportamento entre os dois grupos. Para a estação Jardim Primavera, a média dos dados amostrais obtida no teste $t$ student durante o período da greve foi de $0,008 \mu \mathrm{g} \mathrm{m}^{-3}$, sendo $0,011 \mu \mathrm{g} \mathrm{m}^{-3}$ para os períodos exteriores à greve. Em Jardim Guandu a média de concentração para o período da greve foi de $9,66 \mu \mathrm{g} \mathrm{m}^{-3}$; $\mathrm{e}$ nos períodos exteriores à greve, $10,66 \mu \mathrm{g} \mathrm{m}^{-3}$. Assim, pode-se concluir que houve diminuição nas concentrações do poluente nas duas estações (38\% em Jardim Primavera e 9\% em Jardim Guandu) durante o período de greve.

\section{Concentrações de $\mathrm{PM}_{10}$}

Para ambas as estações pode-se observar (Figura 8) que existem diversos dias em que as variações das concentrações do poluente (incluindo suas medianas) ultrapassam os limites estabelecidos pela OMS (PF). Há situações, inclusive, em que se apresentam alguns outliers superiores ao primeiro nível intermediário limítrofe relacionado ao padrão de qualidade do ar (PI-1) estabelecido pelo CONAMA.

Em Jardim Primavera, de uma maneira geral, as variações das faixas de concentração do poluente (e suas medianas) no período de greve apresentaram valores inferiores, quando comparados com os períodos anterior e posterior ao movimento (Figura 8a). Concentrando o foco no período de greve, nota-se grande redução nos valores dos intervalos e nas medianas apresentados nas caixas entre o quinto dia e o nono dia do movimento. Salienta-se que no dia 30 de maio, décimo e último dia de greve, a Polícia Rodoviária Federal estava atuando para a desobstrução de rodovias com o objetivo de permitir a livre circulação dos caminhões tanques para o abastecimento dos postos de combustíveis (BBC-BRASIL, 2018). Nesse sentido, observa-se na caixa apresentada para essa data um aumento das concentrações em relação aos dias anteriores. Além disso, nesse mesmo dia observam-se registros de outliers (marcados como asterisco no gráfico), sendo que um deles atinge a marca de $172 \mu \mathrm{g} \mathrm{m}^{-3}$ (Figura 8a).

Em relação à estação Jardim Guandu, nota-se que as concentrações do poluente referentes ao período da greve foram mais elevadas (Figura 8b). Salienta-se também que nos dias 31 de maio e $1^{\circ}$ de junho, os dois dias imediatamente posteriores ao fim da greve, a concentração máxima diária ultrapassou o limite PI-1. Esses dados poderiam ser explicados pelo fato da rodovia BR-465, próxima à estação, ter se constituído 
como uma rota de fuga da rodovia Dutra no sentido Rio de Janeiro, a partir da saída Km 208. Essa rota foi usada pelos caminhoneiros, tanto no período de paralização (buscando contornar o movimento), quanto imediatamente após seu término (BBC-BRASIL, 2018). Assim, o fluxo de caminhões aumentou nessa região, sendo que o material particulado tem como principal fonte de emissão os motores de óleo diesel. A partir do dia 2 de junho, após a normalização da situação, ocorreu uma redução significativa nas variações das concentrações (também nas medianas) apresentadas nas caixas.

a

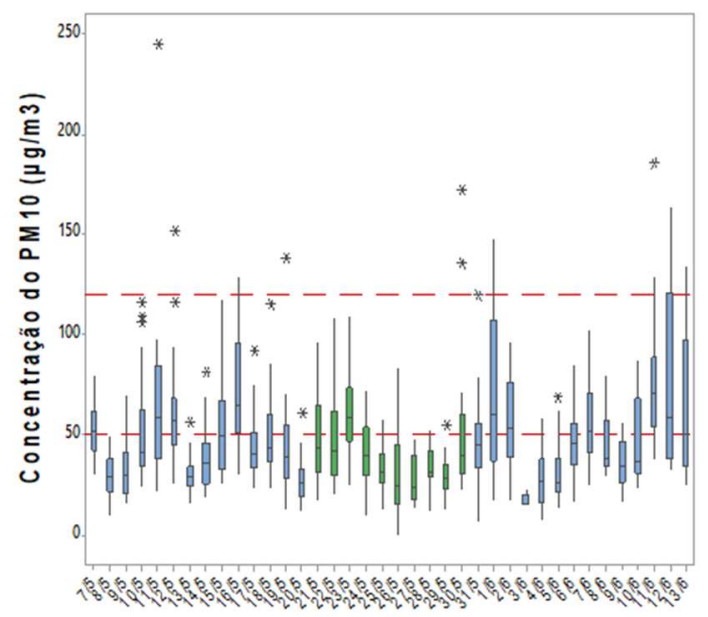

b

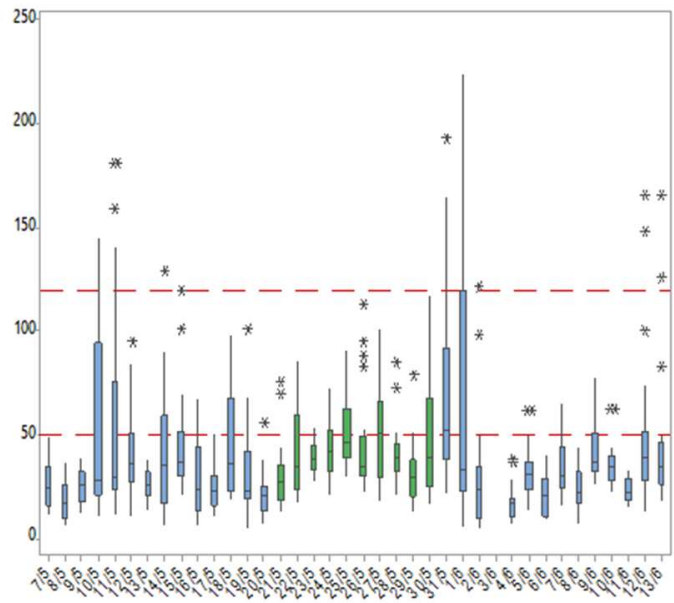

19.96

Figura 8: Variação das concentrações de $\mathrm{PM}_{10}$ - (a) Jardim Primavera, (b) Jardim Guandu.

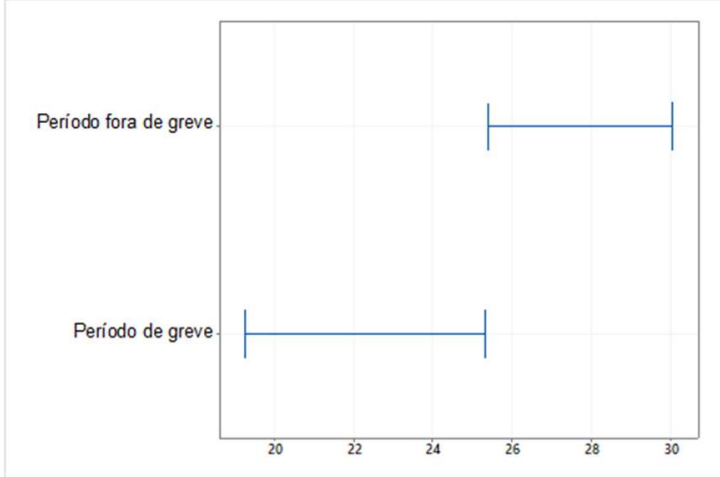

b

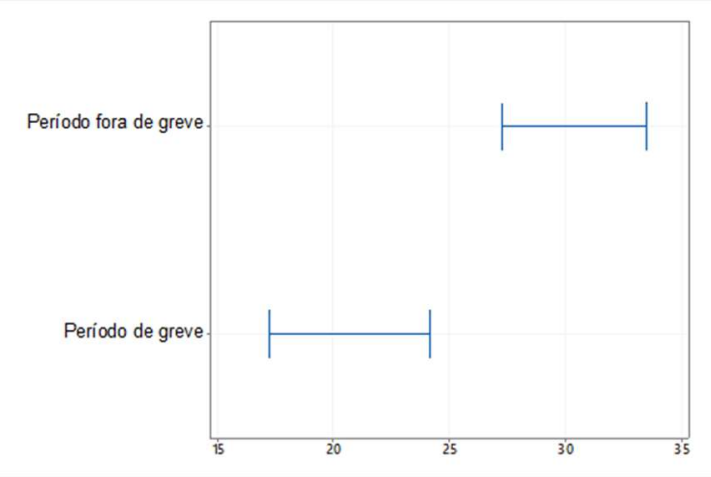

Figura 9: Teste de variâncias iguais - Concentrações de $\mathrm{PM}_{10}$. (a) Jardim Primavera, (b) Jardim Guandu.

O valor de p para o método de comparações múltiplas nas duas estações (0,046 para Jardim Primavera; 0,005 para Jardim Guandu - ver Figura 9) foi inferior a 0,05, indicando a possibilidade de não homogeneidade entre os dois grupos analisados. Passando-se então para o teste $t$ student, $(p=0$ em Jardim primavera; $p=0,002$ em Jardim Guandu), os valores de $p$ indicaram diferenças significativas nas médias dos grupos amostrais. Na estação Jardim Primavera a média obtida de concentração do material particulado para o teste $t$ student foi de $40,5 \mu \mathrm{g} \mathrm{m}^{-3}$ para o período da greve dos caminhoneiros, enquanto para os períodos externos à greve obteve-se uma média de $48,8 \mathrm{\mu g} \mathrm{m}^{-3}$. Desse modo, foi possível enxergar o reflexo da greve, com uma diminuição de $17 \%$ da média das concentrações do material particulado no Jardim Primavera. A estação Jardim Guandu apresentou comportamento inverso, constatando-se um valor médio de concentração do material particulado durante o período de greve igual a $42,1 \mu \mathrm{g} \mathrm{m}^{-3}$, superior aos períodos 
próximos ao movimento, que apresentaram uma média de $36,5 \mu \mathrm{g} \mathrm{m}^{-3}$. Esses dados corroboram as observações apresentadas na análise dos diagramas de caixa para o poluente.

\section{Concentrações de $\mathrm{O}_{3}$}

Em relação à estação Jardim Primavera, o diagrama de caixa (Figura 10a) apresenta, à primeira vista, maiores concentrações de ozônio durante o período de greve, com valores mais significativos entre o quarto e o sétimo dia, incluindo também o nono dia do movimento. No caso de Jardim Guandu (Figura 10b), observase certa uniformidade dos dados, inclusive com a ausência de outliers relacionados às concentrações. Em uma observação visual, nota-se apenas que as variações das concentrações ao longo do período de greve parecem ser maiores, mas dentro de valores não muito superiores aos observados nos períodos anterior e posterior ao movimento, inclusive considerando as medianas nessa avaliação.

a

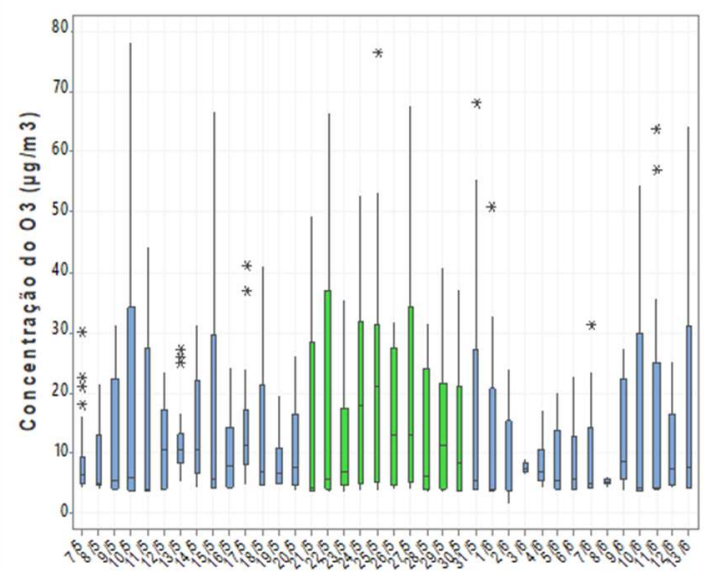

b

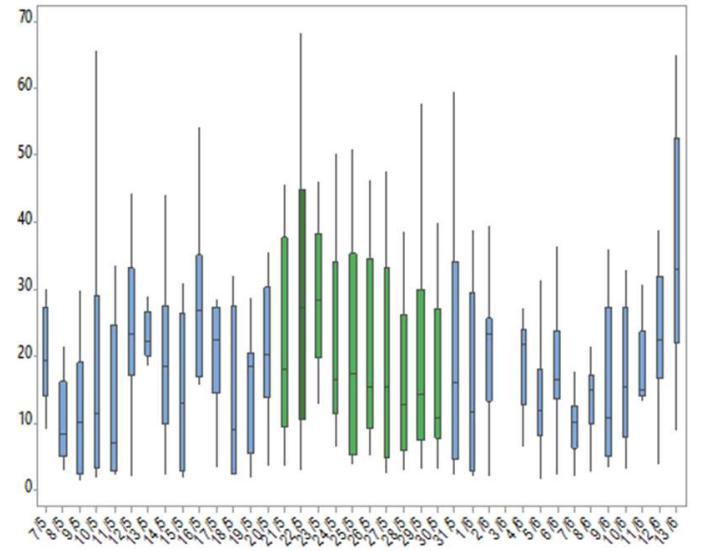

Figura 10: Variação das concentrações de $\mathrm{O}_{3}-$ (a) Jardim Primavera, (b) Jardim Guandu.

Ao se realizar o teste de igualdade de variâncias (Figura 11), obteve-se valores de p para múltiplas comparações iguais a 0,014 (Jardim Primavera) e 0 (Jardim Guandu), rejeitando a hipótese de homogeneidade, podendo-se então considerar que houve diferenças entre os grupos analisados. Na aplicação do teste $t$ student, foi obtido um valor de p igual a 0 para ambas as estações, indicando diferenças significativas nas médias dos grupos amostrais. Analisando-se então as médias, constatou-se um valor médio de concentração do ozônio na estação Jardim Primavera durante o período de greve igual a $16,4 \mu \mathrm{g} \mathrm{m}^{-3}$, superior em 36 por cento aos períodos próximos ao movimento, que apresentaram uma média de 12,1 $\mu \mathrm{g}$ $\mathrm{m}^{-3}$. Assim como no caso da estação Jardim Primavera, Jardim Guandu apresentou maior concentração média durante o período de greve $\left(21,8 \mu \mathrm{g} \mathrm{m}^{-3}\right)$ quando comparada aos períodos próximos ao movimento $(18,1 \mu \mathrm{g}$ $\left.\mathrm{m}^{-3}\right)$, com aumento de 20 por cento.

Fazendo uma comparação entre o ozônio e o dióxido de nitrogênio nas duas estações nos dois períodos analisados, observa-se uma relação inversamente proporcional do comportamento dos dois poluentes. Ou seja, no período de greve houve diminuição das concentrações de $\mathrm{NO}_{2}$ e aumento das concentrações de $\mathrm{O}_{3}$ em ambas as estações. Além disso, em Jardim Primavera, onde a redução da concentração média de $\mathrm{NO}_{2}$ foi maior, comparada à estação Jardim Guandu (38\% e 9\%, respectivamente), o 
percentual de aumento das concentrações de $\mathrm{O}_{3}$ também foi superior (36\% em Jardim Primavera e 20\% em Jardim Guandu). Esse fato justifica-se uma vez que a formação de ozônio ocorre por uma relação entre Compostos Orgânicos Voláteis (COVs) e Óxidos de Nitrogênio $\left(\mathrm{NO}_{\mathrm{x}}\right)$. A redução de $\mathrm{NO}_{\mathrm{x}}$ nas chamadas condições limitadas de COV, que correspondem a baixas taxas de COV/NO $\mathrm{O}_{3}$ (HEUSS et al., 2003). No período de greve ocorreu uma redução na concentração de $\mathrm{NO}_{2}$ nas estações, porém com uma manutenção nas emissões de COVs, em especial aqueles com maior reatividade, oriundos das atividades da Refinaria Duque de Caxias, que não foram interrompidas. Salienta-se que estudo de Dantas et al. (2019) corrobora essas relações, em análise do comportamento dos poluentes no período de greve em outras 4 estações de monitoramento da qualidade do ar (Tijuca, Irajá, Bangu e Campo Grande) localizadas na região metropolitana do Rio de Janeiro. Trabalho mais recente de Dantas et al. (2020) também chega a conclusões similares ao analisar os efeitos do lockdown parcial no município do Rio de Janeiro devido à doença Covid-19.

a

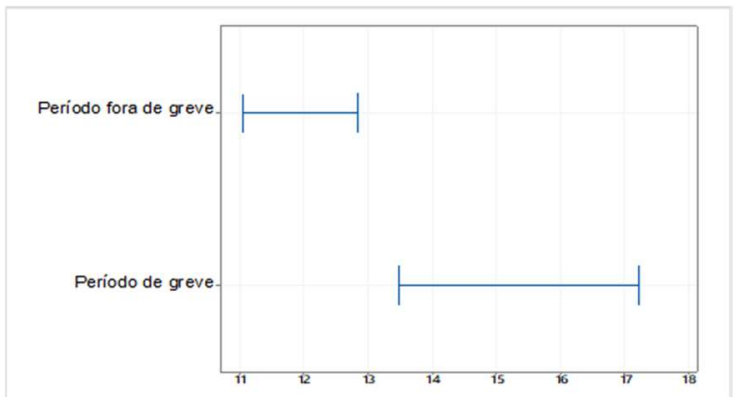

b

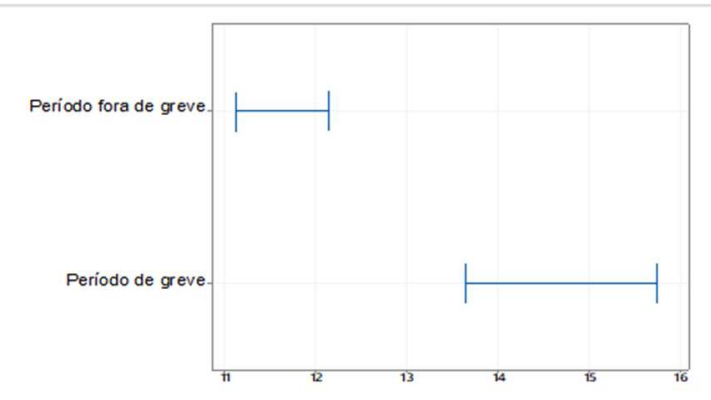

Figura 11: Teste de variâncias iguais - Concentrações de O3. (a) Jardim Primavera, (b) Jardim Guandu.

\section{Análise consolidada dos poluentes}

A Tabela 2 apresenta a consolidação da análise dos 5 poluentes para o período pesquisado.

Tabela 2: Sumário dos resultados referentes às concentrações dos poluentes

\begin{tabular}{|c|c|c|c|c|}
\hline Poluente & Estação & $\begin{array}{l}\text { Houve concentrações } \\
\text { superiores aos limites } \\
\text { da OMS (PF)? }\end{array}$ & $\begin{array}{l}\text { Houve concentrações } \\
\text { superiores ao nível } \\
\text { intermediário } 1(\mathrm{PI}-1) \text { ? }\end{array}$ & $\begin{array}{l}\text { Diferença de comportamento: aumento (+) } \\
\text { ou redução }(-) \text { nas concentrações médias no } \\
\text { período de greve em comparação aos } \\
\text { períodos próximos }\end{array}$ \\
\hline $\mathrm{SO}_{2}$ & $\begin{array}{l}\mathrm{J} \\
\text { Primavera }\end{array}$ & Sim & Não & - \\
\hline $\mathrm{SO}_{2}$ & J Guandu & $\operatorname{Sim}^{1}$ & Não & - \\
\hline $\mathrm{CO}$ & $\begin{array}{l}\text { J } \\
\text { Primavera }\end{array}$ & Não & Não & $-30 \%$ \\
\hline $\mathrm{CO}$ & J Guandu & Não & Não & $-37 \%$ \\
\hline $\mathrm{NO}_{2}$ & $\begin{array}{l}\text { J } \\
\text { Primavera }\end{array}$ & Não & Não & $-38 \%$ \\
\hline $\mathrm{NO}_{2}$ & J Guandu & Não & Não & $-9 \%$ \\
\hline $\mathrm{PM}_{10}$ & $\begin{array}{l}\mathrm{J} \\
\text { Primavera }\end{array}$ & Sim & Sim & $-17 \%$ \\
\hline $\mathrm{PM}_{10}$ & J Guandu & Sim & Sim & $+15 \%$ \\
\hline $\mathrm{O}_{3}$ & $\begin{array}{l}\text { J } \\
\text { Primavera }\end{array}$ & Não & Não & $+36 \%$ \\
\hline $\mathrm{O}_{3}$ & J Guandu & Não & Não & $+20 \%$ \\
\hline
\end{tabular}

(1) Uma vez só no dia 09/06/2018, 13:30.

O dióxido de enxofre é o único poluente que não apresenta diferença de comportamento em ambas 
as estações, comparando-se o período de deflagração da greve e o período próximo a ela, o que poderia ser justificado pela tendência de redução dos teores de enxofre nos combustíveis veiculares. O monóxido de carbono, por sua vez, apresenta uma diminuição de concentração média nas duas estações durante o período da greve, o que pode ser resultado do efeito da paralisação dos veículos automotores nesse período. 0 dióxido de nitrogênio também apresenta menor concentração na sua distribuição estatística durante o período de greve em ambas as estações, sendo essa redução mais significativa na estação Jardim Primavera. Já o material particulado apresentou redução das concentrações na faixa de $17 \%$ durante a greve, em Jardim Primavera, mas com elevação de 15\% em Jardim Guandu no mesmo período. Conforme mencionado, a hipótese para essa elevação seria o uso das vias próximas a Jardim Guandu, menos relevantes e conhecidas, como alternativa de rota de fuga de caminhoneiros sem interesse em participar do movimento durante o período da greve. Finalmente, o ozônio apresentou elevação de suas concentrações durante o período da greve em ambas as estações, sendo essa elevação mais significativa na estação Jardim Primavera. Essa elevação tem relação direta com as reduções nas concentrações de dióxido de nitrogênio no mesmo período.

Cabe ressaltar que em trabalho de um autor, a análise aqui apresentada foi expandida para que fosse considerado o efeito weekend; esse efeito se relaciona às diferenças significativas de comportamento dos poluentes entre dias de semana e fins de semana (HEUSS et al., 2003; MARTINS et al., 2015). A avaliação de um autor se limitou aos fins de semana localizados nos períodos próximos à greve, uma vez que as atividades no período de greve não apresentaram variações significativas entre dias úteis, sábados e domingos, devido às próprias características e consequências do movimento para a sociedade. Foram eliminados, desse modo, os dados referentes às seguintes datas, correspondentes a sábados e domingos nos períodos próximos ao movimento: 12/05, 13/05, 18/05, 19/05, 02/06, 03/06, 09/06 e 10/06. Os resultados obtidos nos testes de igualdade de variâncias, considerando o efeito weekend, para os diferentes poluentes e os dois períodos distintos (dentro e fora da greve) apresentaram pequenas diferenças nas métricas obtidas; apesar dessas pequenas diferenças, os comportamentos das concentrações para todos os poluentes analisados mantiveram tendência igual à apresentada nos resultados consolidados na Tabela 2.

\section{CONCLUSÕES}

O presente trabalho partiu da hipótese de que a greve dos caminhoneiros, realizada no ano de 2018, pode ter causado impactos nas concentrações dos poluentes atmosféricos. A pesquisa indicou que o único poluente que não apresentou variações de comportamento significativas nas estações analisadas, ao se comparar o período de greve com os períodos próximos a ela, foi o dióxido de enxofre. Observou-se redução nos níveis de concentração de monóxido de carbono e dióxido de nitrogênio em ambas as estações no período de greve. Essa redução também foi identificada para o material particulado, mas somente na estação Jardim Primavera, podendo-se explicar o aumento desse poluente em Jardim Guandu pelo fato de os caminhoneiros terem usado as vias próximas a essa estação como rota de fuga no período do movimento. 0 ozônio, por sua vez, apresentou comportamento completamente distinto, apresentando níveis mais elevados de concentração ao longo da greve, efeito das relações de $\mathrm{COVs} / \mathrm{NO}_{x}$ para a formação do poluente. 
Diante do exposto, e apesar de se ter verificado alterações nas concentrações dos poluentes atmosféricos, não é possível indicar uma melhoria significativa na qualidade do ar, sobretudo devido ao aumento das concentrações de ozônio troposférico, sendo este poluente um dos principais causadores de episódios de poluição atmosférica na região metropolitana do Rio de Janeiro.

Como sugestão de trabalhos futuros, a análise aqui desenvolvida poderia ser expandida para outras estações do estado do Rio de Janeiro e do país, considerando-se também as características das estações, de acordo com a localização, em áreas industriais, rurais ou urbanas. Uma avaliação mais ampliada poderia levantar comportamentos semelhantes em diferentes estações, de acordo com as características de suas localizações. Além disso, ao se trabalhar com um número maior de estações em locais distintos, sugere-se complementar a análise com a inclusão das variáveis meteorológicas presentes nos diferentes locais, no momento das medições dos poluentes.

Independentemente dessa análise ser passível de ampliação, acredita-se que o presente trabalho possa contribuir para a identificação dos impactos, em termos de poluição atmosférica, causados pela opção preferencial dada aos caminhões para o transporte das cargas no Brasil.

\section{REFERÊNCIAS}

BBC-BRASIL. Greve dos Caminhoneiros: a cronologia dos 10 dias que pararam o Brasil. BBC-BRASIL, 2018.

CASTRO, A. H. S.; ARAÚJO, R. S.; SILVA; G. M. M.. Qualidade do ar - parâmetros de controle e efeitos na saúde humana uma breve revisão. Holos, v.29, n.5, p.107-121, 2013. DOI: https://doi.org/10.15628/holos.2013.1242

CHAMBERS, J. M.. Graphical methods for data analysis. Wadsworth International Group, 1983.

COHEN, A. J.; BRAUER, M.; BURNETT, R.; ANDERSON, H. R.; FROSTAD, J.; ESTEP, K.; BALAKRISHNAN, K.; BRUNEKREEF, B.; DANDONA, L.; DANDONA, R.. Estimates and 25-year trends of the global burden of disease attributable to ambient air pollution: an analysis of data from the Global Burden of Diseases Study 2015. The Lancet, v.389, n.10082, p.19071918, 2017. DOI: https://doi.org/10.1016/S01406736(17)30505-6

CONAMA. Conselho Nacional do Meio Ambiente. Ministério do Meio Ambiente. Resolução № 491, de 19 de novembro de 2018. Dispõe sobre padrões de qualidade do ar. Brasília: MMA, 2018.

DANTAS, G.; SICILIANO, B.; FREITAS, L.; SEIXAS, E. G.; SILVA, C. M.; ARBILLA, G.. Why did ozone levels remain high in Rio de Janeiro during the Brazilian truck driver strike?.

Atmospheric Pollution Research, v.10, p.2018-2029, 2019. DOI: https://doi.org/10.1016/j.apr.2019.09.010

DANTAS, G.; SICILIANO, B; FRANÇA, B. B.; SILVA, C. M.; ARBILLA, G.. The impact of COVID-19 partial lockdown on the air quality of the city of Rio de Janeiro, Brazil. Science of the Total Environment, v.729, p.139085, 2020. DOI: https://doi.org/10.1016/j.scitotenv.2020.139085
DAWSON, R.. How Significant is a Boxplot Outlier?. Journal of Statistics Education, v.19, n.2, 2011. DOI: https://doi.org/https://doi.org/10.1080/10691898.2011.118 $\underline{89610}$

RIO DE JANEIRO. Decreto n. 22.599 de 01 de novembro de 1996. Dispõe sobre o controle, pelo DETRAN/RJ, da emissão de gases poluentes. Rio de Janeiro: DOE, 1996.

HEUSS, J. M.; KAHLBAUM D. F.; WOLF, G. T. Weekday/weekend ozone differences: what can we learn from them?. J. Air Waste Manag. Assoc., v.53, n.7, p.772788, 2003. DOI:

http://doi.org/10.1080/10473289.2003.10466227

INEA. Instituto Estadual do Ambiente. Relatório da qualidade do ar do Estado de Rio de Janeiro. Rio de Janeiro: INEA, 2015

JAYALATH, K. P.; NG, H. K. T.; MANAGE, A. B.; RIGGS, K. E.. Improved tests for homogeneity of variances. Communications in Statistics-Simulation and Computation v.46, n.9, p.7423-7446, 2017. DOI: https://doi.org/10.1080/03610918.2016.1241404

KARIMI, B.; SHOKRINEZHAD, B.. Air pollution and mortality among infant and children under five years: A systematic review and meta-analysis. Atmospheric Pollution Research, v.11, n.6, p.61-70, 2020. DOI: https://doi.org/10.1016/j.apr.2020.02.006

LIMA, L.. O mercado de Trabalho dos motoristas de caminhão no Brasil: caracterização e avaliação do efeito de leis trabalhistas. Dissertação (Mestrado em Economia Aplicada) - Universidade de São Paulo, São Paulo, 2018.

MANNUCCI, P. M.; HARARI, S.; MARTINELLI, I.; FRANCHINI, $M$.. Effects on health of air pollution: a narrative review. 
Internal and Emergency Medicine, v.10, p.657-662, 2015. DOI: https://doi.org/10.1007/s11739-015-1276-7

MARTINS, E. M.; NUNES, A. C. L.; CORRÊA, S.. Understanding ozone concentrations during weekdays and weekends in the urban area of the city of Rio de Janeiro. Journal of the Brazilian Chemical Society, v.26, n.10, p.1967-1975, 2015. DOI: https://doi.org/10.5935/0103-5053.20150175

MELLO, R.; SILVA, J. L.. Avaliação das Concentrações de Material Particulado e de Dióxido de Enxofre Registradas na Cidade do Rio de Janeiro entre os Anos de 2000-2006 e 2010-2014. Anuário do Instituto de Geociências, v.41, n. 3, 2018.

MINITAB. Introdução ao MINITAB 18. Minitab Inc., 2017.

PIRES, D. O.. Inventário de emissões atmosféricas de fontes estacionárias e sua contribuição para a poluição do ar na região metropolitana do Rio de Janeiro. Dissertação (Mestrado em Ciências em Planejamento Energético) Universidade Federal de Rio de Janeiro, Rio de Janeiro, 2005.

REZENDE, F.. Navegação interior: infraestrutura existente, gargalos operacionais, demandas não atendidas e ações de curto prazo. Confederação Nacional do Transporte, 2017.

RUMSEY, D.. Estatística II para leigos. Rio de Janeiro: Alta Books, 2018

TUKEY, J. W.. Exploratory Data Analysis. Addison-Wesley, 1977.

WATANABE, S.; LEITÃO, S.; FERREIRA, J.. Chegou a hora de falar sobre imposto de carbono no Brasil: Lições aprendidas com a greve dos caminhoneiros. Instituto Escolhas, n.1, p.110,2018

A CBPC - Companhia Brasileira de Produção Científica (CNPJ: 11.221.422/0001-03) detém os direitos materiais desta publicação. Os direitos referem-se à publicação do trabalho em qualquer parte do mundo, incluindo os direitos às renovações, expansões e disseminações da contribuição, bem como outros direitos subsidiários. Todos os trabalhos publicados eletronicamente poderão posteriormente ser publicados em coletâneas impressas sob coordenação da Sustenere Publishing, da Companhia Brasileira de Produção Científica e seus parceiros autorizados. Os (as) autores (as) preservam os direitos autorais, mas não têm permissão para a publicação da contribuição em outro meio, impresso ou digital, em português ou em tradução. 